\title{
Position adopted for the post operative patient and its effect on tidal volume
}

\author{
Pinto $V^{1}$, Eriyawa $A^{2}$, Weerasinghe $S^{2}$, Senasinghe $R^{2}$, Rajendran $V^{3}$ \\ Senior Lecturer, Temporary Lecturer ${ }^{2}$, Department of Anaesthesiology, Faculty of Medicine, \\ University of Peradeniya,.Medical Officer ${ }^{3}$, Base Hospital Nawalapitiya, Sri Lanka.
}

*Corresponding author: vasantipinto@yahoo.com

\begin{abstract}
Most techniques used in general anaesthesia interfere with the function of major systems. General anaesthesia is known to cause post-operative atelectasis of the lungs which may lead to increased ventilation perfusion mismatch and complications such as pneumonia. In some instances it is recommended to keep the patient in the semi-recumbent position in the recovery area and the ward until patient is stabilized and in this position respiratory performance, functional residual capacity and clearance of secretions are improved when compared with the supine position,but in clinical practice it is a known fact that the patients may be kept in various positions post operatively. This study was directed to find out the common positions that the patients were nursed in post-operative wards and the impact of such positions on the ventilatory parameters of the patient.
\end{abstract}

Methodology: A cross-sectional descriptive study was carried out amongst all patients who underwent major surgical and gynaecological interventions under general anaesthesia. Randomized sampling was done, and consented 60 patients were studied. Data was collected using an investigator administered questionnaire and spontaneous tidal volume was assessed first in the patients' nursed position and then once the patients are positioned to semi recumbent position, using a Wright's respirometer. The average of three consecutive breaths was obtained.

Results: Total sample of 60 patients were studied out of which, 50 patients were found to have kept (83.33\%) supine, 8 (13.33\%) semi-recumbent and 2 (3.33\%) were kept left lateral 3- 5 hours post-op irrespective of the surgery. Patients kept in semi-recumbent position had a mean tidal volume of $316.25 \mathrm{ml}(\mathrm{n}=8 \mathrm{SD} \pm 39.978 \mathrm{ml})$. The mean tidal volume in supine patients was $217.4 \mathrm{ml}(\mathrm{n}=50 \mathrm{SD} \pm 50.013 \mathrm{ml})$ and the left lateral group was $255 \mathrm{ml}(\mathrm{n}=2)$, whereas after repositioning both groups to the semi-recumbent position, the mean was $283 \mathrm{ml}(\mathrm{n}=50 \mathrm{SD} \pm 52.109 \mathrm{ml})$ in the supine cohort and $315 \mathrm{~m}$ $\mathrm{l}(\mathrm{n}=2)$ in the left lateral cohort. The two-tailed $\mathrm{P}$ value is less than 0.0001.By conventional criteria; this difference is considered to be extremely statistically significant.

Conclusion: Most of the patients in the post-operative wards were kept in the supine position irrespective of surgeries. Repositioning of them to the semi-recumbent position gives better ventilatory parameters. The staff should be instructed to position post operative patients in the semi recumbent position.

Keywords: postoperative positioning; semi-recumbent position; general anaesthesia

\section{Introduction}

Most techniques used in general anaesthesia interfere with the normal functioning of major organ systems. General anaesthesia is known to cause post-operative non obstructive atelectasis of the lungs which may lead to increased ventilation perfusion mismatch and complications such as hypoxia and pneumonia. Changes in body position are known to influence respiratory mechanics ${ }^{1}$. The incidence and complications of atelectasis can be minimized with semi-recumbent position.There is evidence that altering the 
position of the thorax, for example from upright to side-lying, alters the distribution of ventilation in the lungs of younger subjects ${ }^{2,3}$ such that ventilation is preferentiallydistributed to the gravity-dependent region of the lungs. In the upright position, tidal volume $\left(V_{\mathrm{T}}\right)$ increase, due to lowering of the diaphragm and alveolar expansion due to the lungs' own weight. This position will increase oxygenation and prevent other complications as research show that increased tidal volume improved oxygenation ${ }^{4}$. Studies have shown that during the first hrs of abdominal surgery assumption and maintenance of semi recumbent position improves the arterial oxygenation in obese patients ${ }^{5}$. Thus it is recommended to keep the patient in the semi-recumbent position in the recovery and in the ward until the respiratory performance, functional residual capacity, and clearance of secretions are improved. But in the wards it is not unusual to observe that the patients arekept in various positions. The objective of this study was to find out the positionsthe patients were nursed in postoperative wards with the reasons for adopting such positions and to find out the impact of such positions on the tidal volume of the patient.

\section{Materials and Methods}

A cross-sectional descriptive study was carried out. The patients were randomly selected by taking every third patient who underwent major surgical and gynaecological interventions under general anaesthesia during the month of September 2012 in Teaching Hospital, Peradeniya. Surgeries under spinal anaesthesia, neck procedures (thyroidectomy), neurological patients and any medically complicated patients with severe hypertension, ischaemic heart diseases were excluded. After informed verbal consent, 60 subjects were studied. Data were collected using an investigator administered questionnaire and spontaneous tidal volume (STV) was assessed using a Wright's respirometer. The post operative patients were visited after 3-5 hrs post operatively. First the STV was measured in the position they were already being nursed and if no contraindication the patients were placed in the semi recumbent position and the second reading was obtained.The average of three consecutive breaths were taken in each position. Institutional ethical review was obtained. Paired sample statistics was analysed and with the significance level of $p<0.05$ to compare the changes of the two positions.

\section{Results}

Total sample of 60 patients were studied. Out of which, 50 patients were found to have kept (83.33\%) supine, 8 (13.33\%) semi-recumbent (SR) and 2 (3.33\%) were kept left lateral 4- 5 hours post-operatively irrespective of the surgery. Table 1 shows the mean tidal volume of the respective positions and after changing to the semi recumbent position.

The statistical analyses are presented in Table 1, 2 and 3.The two-tailed $P$ value is less than 0.0001.By conventional criteria, this difference is considered to be extremely statistically significant.

Table 1 Spontaneous tidal volume of patients in each position

\begin{tabular}{|l|l|l|l|}
\hline Position & Number & $\begin{array}{l}\text { Mean } \\
\text { Spontaneous } \\
\text { Tidal } \\
\text { volume } \\
\text { SD }\end{array}$ & $\begin{array}{l}\text { After } \\
\text { changing } \\
\text { to SR } \\
\text { position }\end{array}$ \\
\hline Supine & 50 & $\begin{array}{l}217.4 \quad \mathrm{ml} \\
\pm 50.013 \mathrm{ml}\end{array}$ & $\begin{array}{l}283 \mathrm{ml} \\
\pm\end{array}$ \\
& & & $\begin{array}{l}52.109 \\
\mathrm{ml}\end{array}$ \\
& & $316.25 \mathrm{ml}$ & \\
$\begin{array}{l}\text { Semi } \\
\text { recumbent(SR) }\end{array}$ & 8 & $\begin{array}{l} \pm 39.978 \mathrm{ml} \\
255 \mathrm{ml}\end{array}$ & $315 \mathrm{ml}$ \\
\hline
\end{tabular}

Table 2 Paired samples test

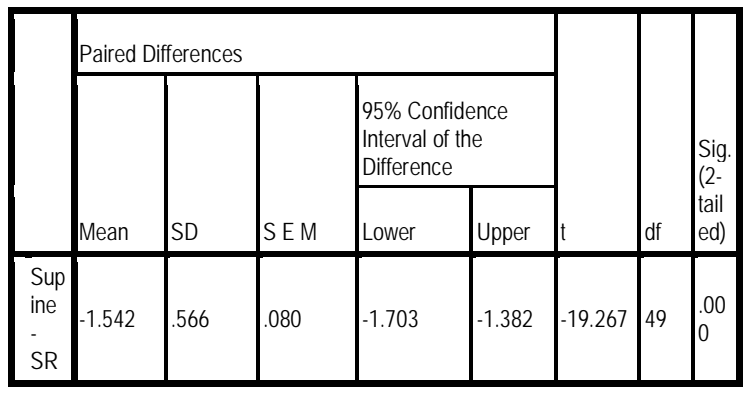

Table 3 Paired samples statistics

\begin{tabular}{lllll}
\hline & Mean & $\mathrm{N}$ & Std. Deviation & $\begin{array}{l}\text { Std.Error } \\
\text { Mean }\end{array}$ \\
\hline Supine & 5.39 & 50 & 0.870 & 0.123 \\
SR & 6.93 & 50 & 1.138 & 0.161 \\
\hline
\end{tabular}


The distribution of the tidal volume in each position is presented in Figure 1 and 2.

Figure 1 Distribution of spontaneous tidal volume $\mathrm{ml} / \mathrm{kg}$ in supine position

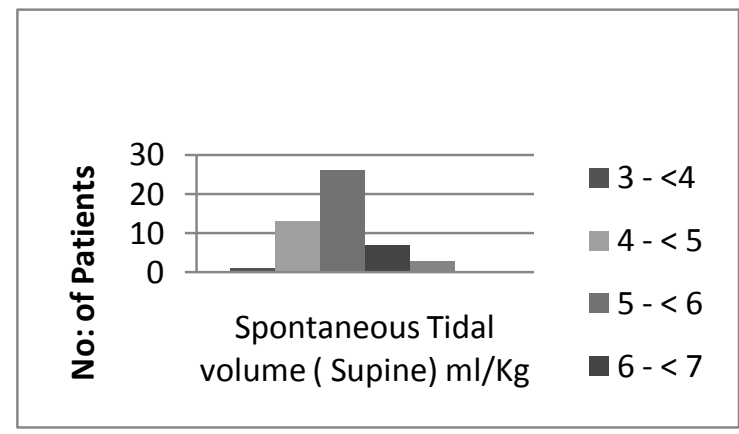

Figure 2- Distribution of spontaneous tidal volume once changed to (semi recumbent) position

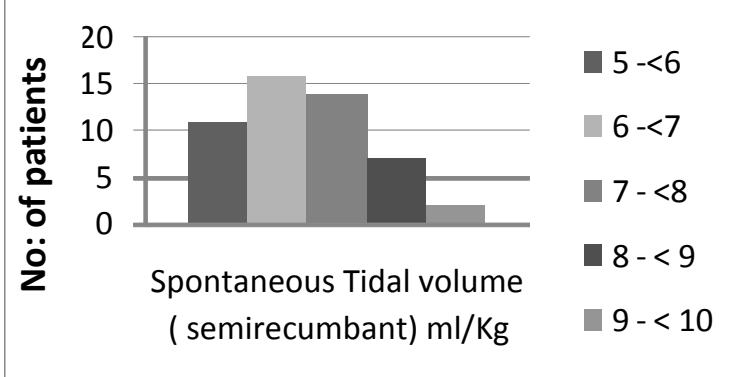

Figure 3 Change of spontaneous tidal volume with patient positioning after general anaesthesia



Table 4 Reasons for adopted position in post operative period other than semi recumbent

\begin{tabular}{|l|c|}
\hline \multicolumn{2}{|l|}{$\begin{array}{l}\text { The reasons given by the nursing staff for } \\
\text { adapted positions }\end{array}$} \\
\hline $\begin{array}{l}\text { No instructions were given in the } \\
\text { post-operative note }\end{array}$ & 48 \\
\hline Traditional teaching & 21 \\
\hline $\begin{array}{l}\text { Thought supine is the best position } \\
\text { for post-operative period }\end{array}$ & 20 \\
\hline
\end{tabular}

Out of interest we also included additional information of the reasons for keeping patients in the explicit positions and presented in Table 4. Due to the overlapping of the result statistical analysis was not done.

\section{Discussion}

The nursing teaching says, when considering semi-conscious patients it is advisable to position in a lateral or semi prone position. ${ }^{6}$ But in novel anaesthetic set up the patients are released to the ward, they are deemed fully awake with functioning reflexes. Hence the above position may have no meaning for adoption. To give more evidence to the position need to adapt research that have suggested that the semi-recumbent posture is a valuable therapeutic modality to improve arterial oxygenation after major abdominal surgery ${ }^{5,7}$.

Post-operative patient should be positioned, unless contraindicated due to medical or other reasons, in a semi-recumbent position.

In this study we only considered patients who underwent general anaesthesia. A significant change in the spontaneous tidal volume after repositioning to semi recumbent position was shown when patients were changed from their initial nursed position of left lateral and supine positions. When analyzing tidal volumes, out of those two positions the spontaneous tidal volumes in left lateral position showed much better readings compared to the supine. When analyzing tidal volume $\mathrm{ml} / \mathrm{kg}$, in the supine position, it was very alarming to note that most patients were kept with highly inadequate tidal volumes like $3-4 \mathrm{ml} / \mathrm{kg}$ or $4-5 \mathrm{ml} / \mathrm{kg}$ (Figure 1 ) .Also it showed that when they were changed to semi recumbent position most were able to ventilate with better tidal volumes (Figure 2). When analyzing individual patients, it was shown that each patient had a rise in the tidal volume to an acceptable level (Figure 3), which was statistically significant. (Table 2,3). In current hospital setup patients are kept in supine position by removing the pillow soon after arrival to the ward post operatively. On further inquiry from the nursing staff it was revealed that they believe keeping the pillow will flex the neck which can obstruct the airway. To achieve semi recumbent position and to avoid neck flexion a larger pillow can be kept supporting both head and shoulders or ideally adjustable beds can be used for postoperative patients.When considering the 
reasons given by nursing staff for the adopted positions (Table 4), achieving above methods of positioning by giving proper training and education will not be a difficult task.

\section{Conclusion}

Most of the patients in the post-operative wards were kept in the supine position irrespective of surgeries. Repositioning of them to the semirecumbent position gives better tidal volumes. The staff should be instructed to position patients in a semi recumbent position; the postoperative notes need to carry instructions regarding patients' nursing position and facilities should be made available to keep the patients in a semi recumbent position.

\section{References}

1. Ibanez J, Raurich JM, Abizanda R, et al. The effect of lateral positions on gas exchange in patients with unilateral lung disease during mechanical ventilation. Intensive Care Med. 1981;7:231-234.

http://dx.doi.org/10.1007/BF01702625 PMid:6792251

2. Amis TC, Jones HA, Hughes JMB. Effect of posture on inter-regional distribution of pulmonary ventilation in man. Respiration Physiology1984:56:145-165. http://dx.doi.org/10.1016/0034-5687(84)90100$\underline{2}$

3. Demedts M. Regional distribution of lung volumes and of gas inspired at residual volume: influence of age, body weight and posture. Bulletin Européen de Physiopathologie Respiratoire.1980:16:271-285. PMid:7397438

4. Visick WD, Fairley HB, Hickey RF. The effects of tidal volume and end-expiratory pressure on pulmonary gas exchange during anaesthesia. Anesthesiology 1973: 39: 285-90. http://dx.doi.org/10.1097/00000542-197309000$\underline{00005}$ PMid:4580631

5. Vaughan RW, Bauer S, Wise L, Effect of position (semi recumbent versus supine) on postoperative oxygenation in markedly obese subjects. Anesth Analg. 1976 Jan-Feb;55(1):3741.

http://dx.doi.org/10.1213/00000539-197601000$\underline{00008}$

PMid:1108708

6. Jennie April Walker, BSc Hons, RN, DipCPC. Staff Nurse, Spinal Trauma and Disorders Unit, Queens Medical Centre, Nottingham http://www.nursingtimes.net/care-of-thepostoperative-patient/2004.
7. Yamagishi T, Ishikawa S, Ohtaki A, Takahashi T, Ohki S, Morishita Y. Obesity and postoperative oxygenation after coronary artery bypass grafting. Jpn J Thorac Cardiovasc Surg. $2000 \quad$ Oct; 48(10):632-6. http://dx.doi.org/10.1007/BF03218218 PMid:11080950

8. Krieg S, Alison JA, McCarren B, Cowell S. Position affects distribution of ventilation in the lungs of older people: an experimental study. Australian Journal of Physiotherapy. 2007: 53: 179-184

http://dx.doi.org/10.1016/S00049514(07)70025-9

9. Burns SM, Egloff MB, Ryan B, Carpenter R, Burns JE., Effect of body position on spontaneous respiratory rate and tidal volume in patients with obesity, abdominal distension and ascites. Am J Crit Care. 1994 Mar; 3(2):102-6. PMid:8167771

10. Frerichs I, Schiffmann H, Oehler R, et al. Distribution of lung ventilation in spontaneously breathing neonates lying in different body positions. Intensive care Medicine: 2003 May; Volume 29, Issue 5: $787 \quad$ - 794 PMid:12665999 